\title{
Sibling Relationships, Personality Traits, Emotional, and Behavioral Difficulties in Autism Spectrum Disorders
}

\author{
C. Longobardi $\mathbb{D}^{1},{ }^{1}$ L. E. Prino $\mathbb{D}^{2},{ }^{2}$ F. G. M. Gastaldi, ${ }^{1}$ and T. Jungert ${ }^{3}$ \\ ${ }^{1}$ Department of Psychology, University of Turin, Via Verdi, 10, Italy \\ ${ }^{2}$ Department of Philosophy and Educational Science, University of Turin, Via Gaudenzio Ferrari, 9, Italy \\ ${ }^{3}$ University of Lund, Department of Psychology, Sweden
}

Correspondence should be addressed to L. E. Prino; lauraelvira.prino@unito.it

Received 9 April 2019; Revised 4 August 2019; Accepted 16 August 2019; Published 25 November 2019

Academic Editor: Elena Nicoladis

Copyright (c) 2019 C. Longobardi et al. This is an open access article distributed under the Creative Commons Attribution License, which permits unrestricted use, distribution, and reproduction in any medium, provided the original work is properly cited.

\begin{abstract}
This study focused on parents' perceptions of the quality of sibling relationship and its association with some behavioral and emotional characteristics of the typically developing sibling. The participants were parents of children with autism spectrum disorder and typically developing siblings. The sample size was 43 . The group comprised 14 fathers $(32.6 \%)$ and 29 mothers $(67.4 \%)$ aged 33-53 years $(M=43.56$; $S D=5.23)$. The parents completed measures of siblings' emotional and behavioral difficulties, siblings' personality, and sibling relationships and their impact on families and siblings. The results showed that behavioral difficulties such as emotional symptoms, conduct problems, hyperactivity/inattention, and peer relationship problems were significantly associated with negative sibling relationships-characterized by rivalry, aggression, avoidance, and teaching behavior toward the brother or sister with an autism spectrum disorder. The implications are that sibling-focused interventions should focus on improving negative sibling relationships to reduce the impact on the difficulties of the typical development of the sibling of both genders and shape the content and delivery framework accordingly. This can be done by providing skills and approaches for enhancing sibling relationships so both parties benefit.
\end{abstract}

\section{Introduction}

For many decades, research on the effects children with disabilities have on families has focused on parents-mothers in particular-although the relationship with siblings is one of the most enduring aspects of an individual's life and can affect adaptation and well-being throughout the entire period of development. A positive relationship with one's siblingsmarked by warmth, affection, and emotional and practical support-is correlated with psychological well-being, while a negative relationship correlates with negative psychological adaptation [1]. It was during the 1980s that research finally focused on siblings, analyzing the effects of the presence of a child with a disability on the other siblings in-depth $[2,3,4]$. The literature on the effects of growing up with a disabled sibling-in particular, one with an autism spectrum disorder (ASD) - is incomplete, and there is much that needs to be clarified. Due to the relatively small sample sizes of the existing studies, as well as the differences in methodology, a number of conflicting results have emerged $[5,6]$.
Research analyzing the effects of the presence of a child with a disability on the other siblings in the family has produced contradictory results. Several studies have highlighted a series of risks for typically developing (TD) siblings-such as solitude and annoyance at the other sibling's behavior $[7,8]$, internalization and externalization of problems $[9,10]$, attention deficits [11], reduced sibling interaction [12], and peer relationship problems $[13,14]$.

ASD can threaten the quality of sibling relationships. This is mainly due to the limited repertoire of social skills and play behaviors and the impairment of communication and social response skills that characterize children with ASD $[15,16]$. These deficits often appear alongside problem behaviors such as physical aggressiveness, a proneness to throwing tantrums, and a destructive attitude when playing with toys $[17,18]$. Consequently, siblings of children with ASD report that sometimes they are disturbed by the behavior of their brother or sister $[12,19]$. Furthermore, children with ASD seem to spend less time with their siblings compared to children with down syndrome or TD children. Some studies [20, 21, 22] have 
pointed out that the siblings of children with ASD tend to be more tolerant than the siblings of non-ASD children but also suffer from higher levels of embarrassment, the fear of being judged by friends and relatives, and the feeling that they cannot share the burden of their experience with their friends.

Other difficulties and problems might emerge from the sense of guilt that follows the realization of one's own "normality" compared to the other sibling's "vulnerability" and the fear that one might develop a disability [23]. In addition, there may also be feelings of resentment and envy toward siblings with disabilities because they might be seen as receiving all the parental attention [24].

Conversely, various studies have also focused on the positive aspects of having a sibling with ASD. Specifically, children with an autistic brother or sister seem to have a relationship that is characterized by less conflict and competitiveness [25] and more warmth [9] compared to relationships between TD siblings. Furthermore, these siblings have better scholastic and behavioral adjustment and positive self-concepts [26], and they report more admiration toward their atypically developing brothers and sisters compared to the siblings of TD children.

Nevertheless, siblings of children with ASD also experience numerous difficulties - such as receiving less parental attention and having more chores around the house, which results in less free time to spend with friends [3], as well as experiencing higher parental pressure (since parents often rely on them to compensate for the limits of their sibling with ASD). These difficulties are shared with the siblings of children with other disabilities, but some features are specific to siblings of children with ASD. For example, siblings of children with ASD experience more embarrassment from strangers' reactions to their brother or sister's stereotyped behaviors [27] and suffer more violent behavior from them [7]. Consequently, researchers have asked themselves if siblings of children with ASD are more at risk of developing psychosocial adjustment problems compared to those with non-ASD siblings. To evaluate this, researchers have often considered the presence of problem behaviors that are externalizing (e.g., hyperactivity and aggressiveness) and internalizing (e.g., somatization, anxiety, and depression). Studies have yielded conflicting results on the issue of sibling adjustment, with a number of them reporting higher externalizing and internalizing problems in children that have a sister or brother with ASD $[7,28,29]$, while others did not find any significant differences between them and the siblings of children with other disabilities or typical development $[30,6]$. At this point, it is difficult to draw firm conclusions on the effect of having a brother or sister with ASD [31].

The quality of the relationship with siblings also seems to affect the individual's personality traits. For instance, according to some studies, less conflict and rivalry and more warmth in relationships lead to greater agreeableness in children and young adults $[32,33,34]$. Considering the risk of a poor quality relationship with a sibling affected by ASD, the latter's possible negative impact on the adaptation of the TD sibling, and the emotional experiences triggered by his/her sibling's disability, it seems important to investigate whether, as mentioned above, having a sibling with ASD can affect the personality traits of the TD sibling. While some studies have investigated the personality traits of children with ASD [35], the literature contains no research focusing on the TD siblings of individuals with ASD.

Meadan et al. [36] highlighted that the family structure can partially explain the variability, but more studies are necessary to deeply analyze predictors of adjustment of TD siblings. One aspect that must be taken into account in studies on the relationship between TD siblings and siblings with ASD is gender. Females tend to be more involved in the management of siblings with intellectual disabilities and are more at risk of developing anxiety-depressive symptoms [37, 38]. However, not all studies find females at greater risk of symptoms of anxiety and maladjustment [39]. Moreover, having a sister with ASD has proved to be associated with a better quality relationship and better psychological adaptation in TD siblings [40].

The birth order is another relevant characteristic of the family structure that has been studied. Younger siblings can be in a disadvantageous condition as a result of the dilution of family resources [41]; this is even more evident when the older child presents special needs $[42,43]$. TD children born after their siblings with ASD are more at risk of maladjustment $[10,44]$. Tomeny et al. [43], in particular, reported that when older siblings with ASD have high levels of externalizing behavior, the younger TD siblings are more at risk of exhibiting externalizing problems. These results are congruent with studies on sibling relationships among TD children [42] and consistent with theories of social learning and modeling. Nevertheless, the literature on the dilution effect is not consistent. Lawson and Mace [45], for example, observed a higher level of prosocial behavior and cooperative abilities in youngest siblings.

Given these contradictory data, this study focuses on parents' perceptions of the quality of the siblings' relationships and their associations with some of the behavioral, emotional, and personality characteristics of the TD siblings. This study is grounded in the family systems model which includes the following four components: social support and resources, family strengths, capacity-building and help-giving practices, and family needs (concerns and priorities). Our focus is on the social support and resources component. From this perspective, the well-being of one family member is likely to affect the well-being of other individuals within the family and sibling relationships highlighted in the current study. In particular, the aim is to analyze, in greater depth, how sibling relationship can affect the development of emotional and behavioral difficulties, as well as the personality of the TD siblings, in the presence of a disability such as ASD. As a secondary aim, this study will investigate whether there are gender differences and differences related to the birth order of the TD sibling in relation to their diagnosed sibling.

Taking the international literature into account, we hypothesize that there is a positive correlation between a positive sibling relationship and strengths and a negative correlation with psychological difficulties. Conversely, we hypothesize that there is a negative correlation between a negative sibling relationship and strengths and a positive correlation with psychological difficulties. On the issue of gender, 
we hypothesize that nonASD female siblings experience more anxiety than their male counterparts. We also hypothesize that based on the gender of the sibling with ASD and the TD sibling, there may be differences in some personality traits-such as extroversion (higher among females).

\section{Method}

2.1. Participants and Procedure. The participants were parents of children with ASD and TD siblings. The sample size was 43. The group comprised 14 fathers (32.6\%) and 29 mothers $(67.4 \%)$ aged $33-53$ years $(M=43.56$; $S D=5.23)$. Among the participants, $62.8 \%$ were parents of children who had been diagnosed with autism, while $37.2 \%$ were parents of children who had been diagnosed with Asperger syndrome. In all, the parents had 22 sons (51\%) and 21 daughters (49\%) without diagnosis aged 6-15 years $(M=10.20 ; S D=2.88)$ and 35 sons (81\%) and 8 daughters (19\%) with ASD aged $3-14$ years $(M=8.52 ; S D=3.17)$. About $33 \%$ of the siblings with diagnoses were firstborns, and $67 \%$ of the siblings with diagnoses were secondborns. The parents responded to the questionnaires with reference to their TD children and their relationships with the siblings with ASD, supported by the researcher.

The University of Turin IRB approved the study (protocol no. 47504). All the participants were contacted through associations that deal with ASD that showed interest in our study.

\subsection{Instruments}

2.2.1. Sibling Inventory of Behavior [46, 47]. This instrument is used to assess sibling relationships in families with and without children with disabilities. The Sibling Inventory of Behavior (SIB) consists of 32 items that assess one sibling's behavior toward the other and measure six dimensions of sibling behavior on a five-point Likert scale $(1=$ Never; $5=$ Always). The six dimensions are: (a) empathy/concern, (b) companionship/involvement, (c) rivalry, (d) conflict/ aggression, (e) avoidance, and (f) teach/directiveness scale. These six dimensions can be further divided into two general dimensions: positive (i.e., empathy/concern, companionship/ involvement, and teach/directiveness) and negative (i.e., rivalry, conflict/aggression, and avoidance). The parents were asked to fill out the questionnaire referring to the way the sibling with typical development related to the other sibling. The scale was translated into Italian, following the criteria established by Van de Vijver and Hambleton [48]. The two general dimensions had acceptable alpha values $(\alpha=.91$ for the positive dimension that measures empathy/concern, companionship/involvement, and teach/directiveness and $\alpha=.86$ for the negative dimension measuring rivalry, conflict/ aggression, and avoidance).

2.2.2. Strengths and Difficulties Questionnaire [49, 50]. This instrument is a brief behavioral screening questionnaire consisting of 25 items on psychological attributes, both positive and negative, divided into 5 subscales, of which the first 4 constitute difficulties-(a) emotional symptoms, (b) conduct problems, (c) hyperactivity/inattention, and (d) peer relationship problems-while the 5th measures strengths, (e) prosocial behavior. Points 1-4 make up the Total Difficulties Score. Each item is answered on a three-point Likert scale ( $1=$ Not true, $3=$ Certainly true). The Italian parent version for children/teens aged between 4 and 17 years $[51,52]$ used in this study showed good reliability. Both the scale measuring strengths and the one measuring difficulties had acceptable alpha values ( $\alpha=.79$ for strengths and $\alpha=.88$ for difficulties).

\subsubsection{Hierarchical Personality Inventory for Children [53, 54,}

55]. This instrument is a developmentally appropriate parentreport measure of the five-factor model for personality (i.e., Big Five; Goldberg [56]) to be used with children aged between 6 and 12 years. More specifically, the dimensions are: emotional stability (anxiety and self-confidence; $\alpha=.71$ ), extraversion (energy, expressivity, shyness, and optimism; $\alpha=.72$ ), imagination (creativity, intellect, and curiosity; $\alpha=.85$ ), benevolence (irritability, egocentrism, compliance, dominance, and altruism; $\alpha=.86$ ), and conscientiousness (order, achievement/motivation, perseverance, and concentration; $\alpha=.67)$.

\section{Data Analysis}

First, preliminary analyses were carried out among the study variables. Second, in relation to the first aim of the study, regression analyses, based on the analysis of the covariance matrix, were utilized to examine whether the positive and negative sibling relationships were associated with the development of emotional and behavioral difficulties and personality. Finally, gender differences between siblings with a diagnosis and gender differences between siblings without a diagnosis, as well as differences between TD siblings born before and after their diagnosed sibling, were calculated, using $t$-tests.

\section{Results}

4.1. Correlations and Regressions with Measures of SIB and Strengths and Difficulties. As outlined in Table 1, all correlations among the study variables were in the expected directions and similar for males and females at the point they were entered in the regression equation. It can be seen that positive sibling relationships were significantly and positively related to strengths $(p=.007)$, while negative sibling relationships were significantly and negatively related to strengths $(p=.023)$ and positively related to difficulties $(p<.001)$.

Two separate hierarchical multiple regressions were performed with the dependent variables of prosocial behavior and difficulties. The first set of predictors in each regression was gender, which was represented by a dummy variable indicating whether the siblings were female or male, and the order of birth of the sibling, represented by a dummy variable indicating whether the TD child was born before or after the ASD sibling. Positive as well as negative parent ratings of sibling 
TABLE 1: Cronbach alphas, means, standard deviations, and correlations among positive sibling relationships, negative sibling relationships, strengths (prosocial behavior), and difficulties.

\begin{tabular}{lllccc}
\hline & $\alpha$ & $m(S D)$ & 1 & 2 & 3 \\
\hline (1) Positive sibling relationships & .91 & $3.34(0.68)$ & - & & \\
(2) Negative sibling relationships & .86 & $2.07(0.57)$ & $-.57^{* *}$ & - & \\
(3) Prosocial behavior & .79 & $1.67(0.46)$ & $.41^{* *}$ & $-.35^{*}$ & - \\
(4) Difficulties & .88 & $0.50(0.38)$ & -.25 & $.65^{* *}$ & $-.47^{* *}$ \\
\hline
\end{tabular}
${ }^{*} p<.05,{ }^{* *} p=.01$.

relationships were entered as a second set. Table 2 presents the results.

In the regression of prosocial behaviors, the predictors accounted for a multiple $R$ of $67, R^{2}=.45, F(4,38)=7.91$, $p<.001$. Birth order of the sibling was significantly and negatively associated with prosocial behaviors $(\beta=-.46)$, indicating the diagnosed child displayed more prosocial behavior when the sibling was born before the diagnosed child. Gender was not a significant predictor. Parental ratings of sibling relationships were not associated with prosocial behaviors either. The regression of difficulties was also significant. The predictors accounted for a multiple $R$ of $.71, R^{2}=.50, F(4,38)=9.44$, $p<.001$. Neither the order of the sibling nor gender was significantly associated with difficulties. As hypothesized, parental ratings of negative sibling relationships $(\beta=.88)$ was significantly and positively related to difficulties, whereas positive sibling behaviors was not related to difficulties.

4.2. Differences in Gender and Order of Birth. $t$-tests comparing SIB, strengths, difficulties, and personalities of males and females were carried out between siblings according to both the gender of the sibling with ASD (Table 3) and the gender of the TD siblings (Table 4). When the sibling with a diagnosis was a male, the child with ASD showed significantly more emotional stability and less extroversion, and parents' ratings of the sibling relationship were significantly less positive. The effect sizes were very strong, ranging from a Cohen's $D$ value of .82-.96. When the TD sibling was a male, he had significantly less anxiety and was timider compared to his female counterpart.

$T$-tests comparing the impact of birth order on SIB, strengths, difficulties, and personalities were carried out between siblings born before and after the sibling with ASD according to the TD siblings (Table 5). Two significant differences were found. In cases where the TD sibling was born after the diagnosed sibling, the TD child showed significantly more prosocial behavior and more expressivity compared to the TD siblings born before their siblings with ASD.

\section{Discussion}

Drawing from the literature on ASD, the present investigation was primarily designed to examine whether sibling relationship, in the presence of ASD, influences the development of emotional and behavioral difficulties, as well as the personality of the other TD siblings. The regression analysis shows that behavioral difficulties are related to sibling relationship, which is in line with previous studies [5, 28]. Previously, there was
TABLE 2: Standardized regression coefficients and $t$-tests for sibling relationships, prosocial behaviors, and difficulties.

\begin{tabular}{lcccc}
\hline & \multicolumn{2}{c}{ Pro-social behaviors } & \multicolumn{2}{c}{ Difficulties } \\
\hline & $\beta$ & $t$-test & $\beta$ & $t$-test \\
\hline $\begin{array}{l}\text { Diagnosis } \\
\text { (asperger vs. }\end{array}$ & .02 & .14 & .35 & $2.37^{*}$ \\
$\begin{array}{l}\text { autism) } \\
\text { Order of birth }\end{array}$ & -.46 & $-3.25^{* *}$ & .21 & 1.41 \\
$\begin{array}{l}\text { Negative } \\
\text { sibling } \\
\text { relationships }\end{array}$ & -.26 & -1.43 & .84 & $4.67^{* * *}$ \\
$\begin{array}{l}\text { Positive } \\
\text { sibling } \\
\text { relationships }\end{array}$ & .36 & 1. & .33 & 1.81 \\
$* * * p<.001 ;{ }^{* *} p<.01 ;{ }^{*} p<.05$. & & & \\
\end{tabular}

some evidence that family relationships and process variables may operate differently for different types of families [57]. This study adds to that literature by confirming that behavioral difficulties such as emotional symptoms, conduct problems, hyperactivity/inattention, and peer relationship problems are significantly associated with negative sibling relationshipscharacterized by behaviors of rivalry, aggression, avoidance, and teaching toward the brother or sister with ASD.

Concerning gender differences in sibling relationships and strengths, difficulties, and personalities of the TD children, our findings reveal only a few significant differences between males and females. When the sibling with ASD was a boy, the diagnosed child had more emotional stability and less extroversion and experienced the relationship with the sibling as being significantly less positive. This would suggest that in the case of a male sibling with a diagnosis, in general, the relationship is experienced as less positive than when the diagnosed child is a girl. To the best of our knowledge, there are no previous studies on this topic. Some studies have focused on same-sex or different-sex dyads $[58,59,12,60]$ but not on the differences based on the sex of the sibling with ASD. We think that in future research, it would be interesting to analyze this result more deeply by making a comparison with dyads of TD siblings, for example.

When the nondiagnosed sibling was female, she had significantly more anxiety and was less timid compared to her male counterpart. These results are only partially in line with previous research [61], but the data on this topic are contradictory. On the one hand, some studies involving male siblings have reported a higher risk of depression, lower 
TABLE 3: Mean differences in sibling behavior, strengths, difficulties, and personalities, according to gender of the ASD siblings.

\begin{tabular}{lccc}
\hline Variable & $\begin{array}{c}\text { Female } \\
\text { mean }(S D)\end{array}$ & $\begin{array}{c}\text { Male } \\
\text { mean }(S D)\end{array}$ & $t$-test \\
\hline HIPICEmotional stability & $32.00(6.89)$ & $37.23(5.22)$ & $t(41)=-2.41, p=.021$, C's $d=.86$ \\
HIPICExtraversion & $82.63(10.45)$ & $74.49(9.30)$ & $t(41)=2.19, p=.035$, C's $d=.82$ \\
HIPICBenevolence & $93.50(12.30)$ & $90.63(10.40)$ & - \\
\hline SIB positive sibling relationship & $3.80(0.45)$ & $3.24(0.69)$ & $t(41)=2.21, p=.033$, C's $d=.96$ \\
SIB negative sibling relationship & $1.90(0.34)$ & $2.12(0.61)$ & $1.68(0.49)$ \\
SDQ prosocial behavior & $1.63(0.29)$ & $0.54(0.41)$ & $19.69(4.28)$ \\
SDQ difficulties & $0.35(0.19)$ & $17.54(2.50)$ & $17.31(4.12)$ \\
HIPICEmotional stability, anxiety & $14.75(6.32)$ & $17.83(2.72)$ & \\
HIPICEmotional stability, self-confidence & $17.25(2.25)$ & $20.77(4.71)$ & \\
HIPICExtraversion, energy & $21.00(3.16)$ & $18.57(2.13)$ & \\
HIPICExtraversion, expressivity & $18.38(3.50)$ & $24.77(4.30)$ & \\
HIPICExtraversion, optimism & $23.13(3.36)$ & $13.17(4.46)$ & \\
HIPICExtraversion, shyness & $20.13(2.80)$ & $17.60(2.30)$ & \\
HIPICBenevolence, altruism & $25.25(2.82)$ & $20.23(3.61)$ & \\
HIPICBenevolence, dominance & $14.88(4.94)$ & $14.86(7.23)$ & \\
HIPICBenevolence, egocentrism & $17.63(2.62)$ & & \\
HIPICBenevolence, compliance & $20.75(2.66)$ & $15.00(5.81)$ & \\
HIPICBenevolence, irritability & &
\end{tabular}

TABLE 4: Mean differences in sibling behavior, strengths, difficulties, and personalities, according to gender of TD siblings.

\begin{tabular}{|c|c|c|c|}
\hline Variable & $\begin{array}{c}\text { Female } \\
\text { mean }(S D)\end{array}$ & $\begin{array}{c}\text { Male } \\
\text { mean }(S D)\end{array}$ & $t$-test \\
\hline HIPICEmotional stability & $37.9524(5.95)$ & $34.6364(5.40)$ & ns \\
\hline HIPICExtraversion & $73.8571(11.90)$ & $78.05(7.29)$ & ns \\
\hline HIPICBenevolence & $89.0952(9.88)$ & $93.14(11.26)$ & ns \\
\hline SIB positive sibling relationship & $3.44(0.77)$ & $3.21(0.54)$ & ns \\
\hline$\underline{\text { SIB negative sibling relationship }}$ & $1.95(0.44)$ & $2.22(0.69)$ & ns \\
\hline SDQ prosocial behavior & $1.63(0.48)$ & $1.71(0.44)$ & ns \\
\hline SDQ difficulties & $0.57(0.46)$ & $0.44(0.29)$ & ns \\
\hline HIPICEmotional stability, anxiety & $20.76(4.58)$ & $16.86(4.76)$ & $t(41)=2.73, p=.009$ \\
\hline HIPICEmotional stability, self-confidence & $17.19(3.01)$ & $17.77(1.74)$ & ns \\
\hline HIPICExtraversion, energy & $18.19(4.76)$ & $17.82(3.66)$ & ns \\
\hline HIPICExtraversion, expressivity & $17.48(3.06)$ & $18.36(2.61)$ & ns \\
\hline HIPICExtraversion, optimism & $20.33(5.69)$ & $22.05(3.02)$ & ns \\
\hline HIPICExtraversion, shyness & $17.86(2.10)$ & $19.82(2.13)$ & $t(41)=-3.04, p=.004$ \\
\hline HIPICBenevolence, altruism & $24.14(5.22)$ & $25.55(2.39)$ & ns \\
\hline HIPICBenevolence, dominance & $13.14(4.94)$ & $13.82(4.22)$ & ns \\
\hline HIPICBenevolence, egocentrism & $17.76(2.77)$ & $17.45(1.87)$ & ns \\
\hline HIPICBenevolence, compliance & $19.33(3.94)$ & $21.27(2.62)$ & ns \\
\hline HIPICBenevolence, irritability & $14.71(8.18)$ & $15.05(5.66)$ & ns \\
\hline
\end{tabular}

prosociality $[28,62]$, and overall difficulties, especially in the areas of hyperactivity and peer problems [6], but on the other hand, female siblings are more vulnerable to anxious and depressive symptoms [38]. Lastly, our data revealed that when the TD sibling was born after the diagnosed sibling, the TD child showed significantly more prosocial behaviors and more expressivity compared to TD siblings born before their sibling with ASD. Respect the aims, our data are scarce and a few conclusive. The results seem to contradict previous literature, which seems to indicate worse maladjustment in subjects born after their brothers with ASD [63, 10, 43, 44]. More investigation will be needed on the possible factors that may have influenced the results, including cultural variables. It is possible that prosocial behaviors are the result of learning and modeling, derived from the way parents have taught their brother to assist their brother with ASD. However, this hypothesis has not been investigated and remains speculative at the moment.

This study has some limitations. First of all, the small size of the sample did not allow for more extensive analyses, such as investigations of how sibling gender and birth order may interact. Moreover, we only collected data from parents of siblings. In future research, it would also be important to include self-reports of siblings or to use some observational 
TABLE 5: Mean differences in sibling behavior, strengths, difficulties, and personalities, according to the birth order of the TD siblings.

\begin{tabular}{|c|c|c|c|}
\hline Variable & $\begin{array}{l}\text { Born before sibling mean } \\
(S D)\end{array}$ & $\begin{array}{l}\text { Born after sibling mean } \\
\qquad(S D)\end{array}$ & $t$-test \\
\hline HIPICEmotional stability & $35.1111(6.73)$ & $38.2308(3.42)$ & ns \\
\hline HIPICExtraversion & $76.111(11.14)$ & $76.6923(8.43)$ & ns \\
\hline HIPICBenevolence & $90.000(10.44)$ & $94.9231(11.58)$ & ns \\
\hline SIB positive sibling relationship & $3.65(0.79)$ & $3.15(0.82)$ & ns \\
\hline$\underline{\text { SIB negative sibling relationship }}$ & $1.79(0.57)$ & $2.25(0.98)$ & ns \\
\hline SDQ prosocial behavior & $1.53(0.50)$ & $1.89(0.24)$ & $t(38)=-3.13, p=.003$, C's $d=0.92$ \\
\hline SDQ difficulties & $0.55(0.41)$ & $0.48(0.34)$ & ns \\
\hline HIPICEmotional stability, anxiety & $17.85(5.88)$ & $20.15(2.76)$ & ns \\
\hline HIPICEmotional stability, self-confidence & $17.26(2.60)$ & $18.08(2.22)$ & ns \\
\hline HIPICExtraversion, energy & $18.93(4.30)$ & $16.85(3.87)$ & ns \\
\hline HIPICExtraversion, expressivity & $17.19(2.56)$ & $19.62(2.87)$ & $t(38)=-2.71, p=.010$ \\
\hline HIPICExtraversion, optimism & $21.37(5.46)$ & $21.08(2.60)$ & ns \\
\hline HIPICExtraversion, shyness & $18.63(2.26)$ & $19.15(2.70)$ & ns \\
\hline HIPICBenevolence, altruism & $24.30(4.51)$ & $25.39(3.15)$ & ns \\
\hline HIPICBenevolence, dominance & $13.67(4.70)$ & $14.08(4.42)$ & ns \\
\hline HIPICBenevolence, egocentrism & $17.59(2.61)$ & $18.15(1.57)$ & ns \\
\hline HIPICBenevolence, compliance & $19.67(3.52)$ & $21.77(3.35)$ & ns \\
\hline HIPICBenevolence, irritability & $14.78(7.81)$ & $15.54(5.67)$ & ns \\
\hline
\end{tabular}

data and some clinical scales to reveal personality characteristics and/or specific difficulties and symptoms (such as trait anxiety, anxiety disorders, and depressive symptoms). Other observational tools could be used to assess the quality of the relationship between siblings, and qualitative research could help clarify and interpret the relationship between the variables considered. In addition, it is possible that the behavioral difficulties of TD siblings and their relationships with their siblings with ASD change over time, which may influence the associations between these variables. Longitudinal studies are needed to better understand this. Finally, we did not collect data from a comparison group of only TD siblings. Conversely, the purpose of this study was to focus on the quality of the relationship between a TD child and a sibling with ASD. Future research could also include a comparison group of only TD children. In this direction, future research could compare siblings with different forms of intellectual disability and take into account the degree of severity of such pathology.

It may be too preliminary to suggest changes to interventions based on the results of this stud; however, the implications of the overall results suggest that sibling-focused interventions should focus on improving negative sibling relationships to reduce their impact on the difficulties of the TD sibling of both genders and shape the content and delivery framework accordingly. This could be done by providing skills and approaches for enhancing sibling relationships so both parties can benefit. An example is by enhancing engagement in daily activities, as suggested by McHale et al. [12]. An adequate assessment of the quality of sibling relationships could require psychotherapeutic interventions, which could be conducted by referring to interventions inspired by the theory of attachment or systemic-relational therapy. Psychoeducational interventions and parent training could be aimed at parents to support them in promoting positive relationships between siblings and managing any conflict situations.

\section{Data Availability}

The SPSS data used to support the findings of this study are available from the corresponding author upon request.

\section{Ethical Approval}

All procedures performed in the studies involving human participants were in accordance with the ethical standards of the institutional and/or national research committee and with the 1964 Helsinki Declaration and its later amendments or comparable ethical standards.

\section{Consent}

Informed consent was obtained from all individual participants included in the study.

\section{Conflicts of Interest}

The authors declare that they have no conflicts of interest.

\section{Authors' Contributions}

C. Longobardi: designed and executed the study and wrote the paper. L. E. Prino.: collaborated with analyzing the data and writing the paper. F. G. M. Gastaldi: collaborated with analyzing the data and writing the paper. T. Jungert: 
collaborated with analyzing the data, writing, and editing the manuscript.

\section{References}

[1] E. B. Waite, L. Shanahan, S. D. Calkins, S. P. Keane, and M. O'Brien, "Life events, sibling warmth, and youths' adjustment," Journal of Marriage and the Family, vol. 73, no. 5, pp. 902-912, 2011.

[2] G. H. Brody and Z. Stoneman, "Children with atypical siblings," Advances in Clinical Child Psychology, Springer, Boston, MA, pp. 285-326, 1983.

[3] D. Lobato, "Siblings of handicapped children: a review," Journal of Autism and Developmental Disorders, vol. 13, no. 4, pp. 347-364, 1983.

[4] R. J. Simeonsson and S. M. McHale, "Review: research on handicapped children: sibling relationships," Child: Care, Health and Development, vol. 7, no. 3, pp. 153-171, 1981.

[5] G. M. Griffith, R. P. Hastings, and M. A. Petalas, "Brief report: fathers' and mothers' ratings of behavioral and emotional problems in siblings of children with autism spectrum disorder," Journal of Autism and Developmental Disorders, vol. 44, no. 5, pp. 1230-1235, 2014.

[6] K. M. Walton and B. R. Ingersoll, "Psychosocial adjustment and sibling relationships in siblings of children with autism spectrum disorder: risk and protective factors," Journal of Autism and Developmental Disorders, vol. 45, no. 9, pp. 2764-2778, 2015.

[7] A. Bågenholm and C. Gillberg, "Psychosocial effects on siblings of children with autism and mental retardation: a populationbased study," Journal of Intellectual Disability Research, vol. 35, no. 4, pp. 291-307, 1991.

[8] M. A. Petalas, R. P. Hastings, S. Nash, and S. Duff, “Typicality and subtle difference in sibling relationships: experiences of adolescents with autism," Journal of Child and Family Studies, vol. 24, no. 1, pp. 38-49, 2015.

[9] S. Fisman, L. Wolf, D. Ellison, B. Gillis, T. Freeman, and P. Szatmari, "Risk and protective factors affecting the adjustment of siblings of children with chronic disabilities," Journal of the American Academy of Child \& Adolescent Psychiatry, vol. 35, no. 11, pp. 1532-1541, 1996.

[10] M. A. Petalas, R. P. Hastings, S. Nash, A. Dowey, and D. Reilly, "'I like that he always shows who he is": the perceptions and experiences of siblings with a brother with autism spectrum disorder," International Journal of Disability, Development and Education, vol. 56, no. 4, pp. 381-399, 2009.

[11] Y.-L. Chien, E.-N. Tu, and S. S.-F. Gau, "School functions in unaffected siblings of youths with autism spectrum disorders," Journal of Autism and Developmental Disorders, vol. 47, no. 10, pp. 3059-3071, 2017.

[12] S. M. McHale, K. A. Updegraff, and M. E. Feinberg, "Siblings of youth with autism spectrum disorders: theoretical perspectives on sibling relationships and individual adjustment," Journal of Autism and Developmental Disorders, vol. 46, no. 2, pp. 589-602, 2016.

[13] J. M. Fullerton, V. Totsika, R. Hain, and R. P. Hastings, "Siblings of children with life-limiting conditions: psychological adjustment and sibling relationships," Child: Care, Health and Development, vol. 43, no. 3, pp. 393-400, 2017.

[14] F. Laghi, F. Federico, A. Lonigro et al., "Peer and teacher-selected peer buddies for adolescents with autism spectrum disorders: the role of social, emotional, and mentalizing abilities," The Journal of Psychology, vol. 150, no. 4, pp. 469-484, 2016.

[15] American Psychiatric Association, Diagnostic and Statistical Manual of Mental Disorders (DSM-5 ${ }^{\circ}$ ), American Psychiatric Pub, 2013.

[16] J. L. Sanders and S. B. Morgan, "Family stress and adjustment as perceived by parents of children with autism or down syndrome: implications for intervention," Child \& Family Behavior Therapy, vol. 19, no. 4, pp. 15-32, 1997.

[17] A. G. Dempsey, A. Llorens, C. Brewton, S. Mulchandani, and R. P. Goin-Kochel, "Emotional and behavioral adjustment in typically developing siblings of children with autism spectrum disorders," Journal of Autism and Developmental Disorders, vol. 42, no. 7, pp. 1393-1402, 2012.

[18] G. I. Orsmond and M. M. Seltzer, "Siblings of individuals with autism spectrum disorders across the life course," Mental Retardation and Developmental Disabilities Research Reviews, vol. 13, no. 4, pp. 313-320, 2007.

[19] P. Ross and M. Cuskelly, "Adjustment, sibling problems and coping strategies of brothers and sisters of children with autistic spectrum disorder," Journal of Intellectual \& Developmental Disability, vol. 31, no. 2, pp. 77-86, 2006.

[20] B. Mandleco and A. E. M. Webb, "Sibling perceptions of living with a young person with down syndrome or autism spectrum disorder: an integrated review," Journal for Specialists in Pediatric Nursing, vol. 20, no. 3, pp. 138-156, 2015.

[21] C. A. Pollard, C. M. Barry, B. H. Freedman, and B. A. Kotchick, "Relationship quality as a moderator of anxiety in siblings of children diagnosed with autism spectrum disorders or down syndrome," Journal of Child and Family Studies, vol. 22, no. 5, pp. 647-657, 2013.

[22] P. S. Strain and C. D. Danko, "Caregivers' encouragement of positive interaction between preschoolers with autism and their siblings," Journal of Emotional and Behavioral Disorders, vol. 3, no. 1, pp. 2-12, 1995.

[23] Z. Stoneman and G. H. Brody, "Sibling relations in the family context," The Effects of Mental Retardation, Disability, and Illness on Sibling Relationships: Research Issues and Challenges, Paul H. Brookes Publishing, Baltimore, MD, Englandpp. 3-30, 1993.

[24] J. W. Rivers and Z. Stoneman, "Sibling relationships when a child has autism: marital stress and support coping," Journal of Autism and Developmental Disorders, vol. 33, no. 4, pp. 383-394, 2003.

[25] L. Kaminsky and D. Dewey, "Siblings relationships of children with autism," Journal of Autism and Developmental Disorders, vol. 31, no. 4, pp. 399-410, 2001.

[26] C. P. Mota and P. M. Matos, "Does sibling relationship matter to self-concept and resilience in adolescents under residential care?," Children and Youth Services Review, vol. 56, pp. 97-106, 2015.

[27] S. B. Morgan, "The autistic child and family functioning: a developmental-family systems perspective," Journal of Autism and Developmental Disorders, vol. 18, no. 2, pp. 263-280, 1988.

[28] R. P. Hastings, "Behavioral adjustment of siblings of children with autism engaged in applied behavior analysis early intervention programs: the moderating role of social support," Journal of Autism and Developmental Disorders, vol. 33, no. 2, pp. 141-150, 2003.

[29] L. E. Prino, D. Scigala, M. A. Fabris, and C. Longobardi, "The moderating role of gender in siblings of adults with intellectual 
disabilities," Interpersona: An International Journal on Personal Relationships, vol. 13, no. 1, pp. 1-13, 2019.

[30] F. Laghi, A. Lonigro, S. Pallini et al., "Sibling relationships and family functioning in siblings of early adolescents, adolescents and young adults with autism spectrum disorder," Journal of Child and Family Studies, vol. 27, no. 3, pp. 793-801, 2018.

[31] R. P. Hastings and M. A. Petalas, "Self-reported behaviour problems and sibling relationship quality by siblings of children with autism spectrum disorder," Child: Care, Health and Development, vol. 40, no. 6, pp. 833-839, 2014.

[32] W. Furman and R. P. Lanthier, Sibling Relationships: Their Causes and Consequences Personality and Sibling Relationships, Ablex Publishing, Westport, CT, USApp. 127-146, 1996.

[33] T. Kavčič and M. Zupančič, "Sibling relationship and personality in early/middle childhood from parent's perception," Contemporary Psychology, vol. 14, no. 2, pp. 119-132, 2011.

[34] R. P. Lanthier, "Personality traits and sibling relationships in emerging adults, personality traits and sibling relationships in emerging adults," Psychological Reports, vol. 100, no. 2, pp. 672-674, 2007.

[35] B. Barger, J. Campbell, and C. Simmons, "The five factor personality model in children with ASD during middle childhood," Focus on Autism and Other Developmental Disabilities, vol. 31, no. 3, pp. 174-183, 2016.

[36] H. Meadan, J. B. Stoner, and M. E. Angell, "Review of literature related to social, emotional, and behavioral adjustment of siblings of individuals with autism spectrum disorders," Journal of Developmental and Physical Disabilities, vol. 22, no. 1, pp. 83-100, 2010.

[37] G. I. Orsmond and M. M. Seltzer, "Brothers and sisters of adults with mental retardation: gendered nature of the sibling relationship," American Journal on Mental Retardation, vol. 105, no. 6, pp. 486-507, 2000.

[38] G. I. Orsmond and M. M. Seltzer, "Adolescent siblings of individuals with an autism spectrum disorder: testing a diathesis-stress model of sibling well-being," Journal of Autism and Developmental Disorders, vol. 39, no. 7, pp. 1053-1065, 2009.

[39] C. M. Shivers, L. K. Deisenroth, and J. L. Taylor, "Patterns and predictors of anxiety among siblings of children with autism spectrum disorders," Journal of Autism and Developmental Disorders, vol. 43, no. 6, pp. 1336-1346, 2013.

[40] C. Bontinck, P. Warreyn, S. Van der Paelt, E. Demurie, and H. Roeyers, "The early development of infant siblings of children with autism spectrum disorder: characteristics of sibling interactions," PLoS One, vol. 13, no. 3, Article ID e0193367, , 2018.

[41] D. B. Downey, "Number of siblings and intellectual development," American Psychologist, vol. 56, no. 6-7, pp. 497-504, 2001.

[42] M. Azmitia and J. Hesser, "Why siblings are important agents of cognitive development: a comparison of siblings and peers," Child Development, vol. 64, no. 2, pp. 430-444, 1993.

[43] T. S. Tomeny, T. D. Barry, and S. H. Bader, "Birth order rank as a moderator of the relation between behavior problems among children with an autism spectrum disorder and their siblings," Autism, vol. 18, no. 2, pp. 199-202, 2014.

[44] S. Verté, H. Roeyers, and A. Buysse, "Behavioural problems, social competence, and self-concept in siblings of children with autism," Child: Care Health, and Development, vol. 29, pp. 193-205, 2003.
[45] D. C. Lawson and R. Mace, "Siblings and childhood mental health: evidence for later-born advantage," Social Science \& Medicine, vol. 70, no. 12, pp. 2061-2069, 2010.

[46] E. M. Hetherington, S. H. Henderson, D. Reiss et al., "Adolescent siblings in stepfamilies: family functioning and adolescent adjustment," Monographs of the Society for Research in Child Development, vol. 64, no. 4, pp. 1-25, 1999.

[47] E. S. Schaefer and M. Edgerton, The Sibling Inventory of Behavior, University of North Carolina, Chapel Hill, NC, 1981.

[48] F. Van de Vijver and R. K. Hambleton, "Translating tests," European Psychologist, vol. 1, no. 2, pp. 89-99, 1996.

[49] R. Goodman, "The strengths and difficulties questionnaire: a research note," Journal of Child Psychology and Psychiatry, vol. 38, no. 5, pp. 581-586, 1997.

[50] R. Goodman, H. Meltzer, and V. Bailey, "The strengths and difficulties questionnaire: a pilot study on the validity of the self-report version," European Child \& Adolescent Psychiatry, vol. 7, no. 3, pp. 125-130, 1998.

[51] G. M. Marzocchi, C. Capron, M. Di Pietro et al., "The use of the strengths and difficulties questionnaire (SDQ) in Southern European countries," European Child \& Adolescent Psychiatry, vol. 13, no. 2, pp. ii40-ii46, 2004.

[52] V. Tobia and G. M. Marzocchi, “The strengths and difficulties questionnaire-parents for italian school-aged children: psychometric properties and norms," Child Psychiatry of Human Development, vol. 49, no. 1, pp. 1-8, 2018.

[53] F. De Fruyt, I. Mervielde, and B. De Clercq, HiPIC - Hierarchical Personality Inventory for Children, Hogrefe, Firenze, 2014. https://www.hogrefe.it/catalogo/test/bambini-e-adolescenti/ hipic-hierarchical-personality-inventory-children/

[54] I. Mervielde and F. De Fruyt, "Proceedings of the Eight European Conference on Personality Psychology," Construction of the Hierarchical Personality Inventory for Children (HiPIC). Personality Psychology in Europe, Tilburg University Press, TilburgI. Mervielde, I. Deary, F. De Fruyt, and F. Ostendorf, Ed., pp. 107-127, 1999.

[55] I. Mervielde and F. De Fruyt, Assessing Children's Traits with the Hierarchical Personality Inventory for Children, Hogrefe \& Huber Publishers, Gottingen, 2002.

[56] L. R. Goldberg, "The structure of phenotypic personality traits," American Psychologist, vol. 48, no. 1, pp. 26-34, 1993.

[57] J. H. Bray, "Developmental issues for long-term stepfamilies," The Family Journal, vol. 1, no. 4, pp. 361-364, 1993.

[58] K. L. Buist, "Sibling relationship quality and adolescent delinquency: a latent growth curve approach," Journal of Family Psychology, vol. 24, no. 4, pp. 400-410, 2010.

[59] K. L. Buist, M. Deković, and P. Prinzie, "Sibling relationship quality and psychopathology of children and adolescents: a meta-analysis," Clinical Psychology Review, vol. 33, no. 1, pp. 97-106, 2013.

[60] C. J. Tucker, K. T. Van Gundy, D. Wiesen-Martin, E. H. Sharp, C. J. Rebellon, and N. F. Stracuzzi, "Proactive and reactive sibling aggression and adjustment in adolescence," Journal of Interpersonal Violence, vol. 30, no. 6, pp. 965-987, 2015.

[61] C. P. McLean and E. R. Anderson, "Brave men and timid women? A review of the gender differences in fear and anxiety," Clinical Psychology Review, vol. 29, no. 6, pp. 496-505, 2009.

[62] R. J. Macks and R. E. Reeve, "The adjustment of non-disabled siblings of children with autism," Journal of Autism and Developmental Disorders, vol. 37, no. 6, pp. 1060-1067, 2007. 
[63] M. A. Petalas, R. P. Hastings, S. Nash, T. Lloyd, and A. Dowey, "Emotional and behavioural adjustment in siblings of children with intellectual disability with and without autism," Autism, vol. 13, pp. 471-483, 2009. 


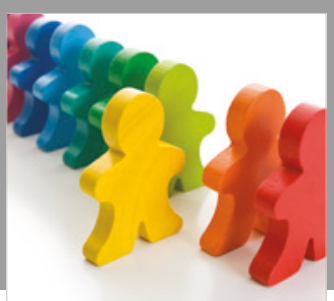

Autism

Research and Treatment
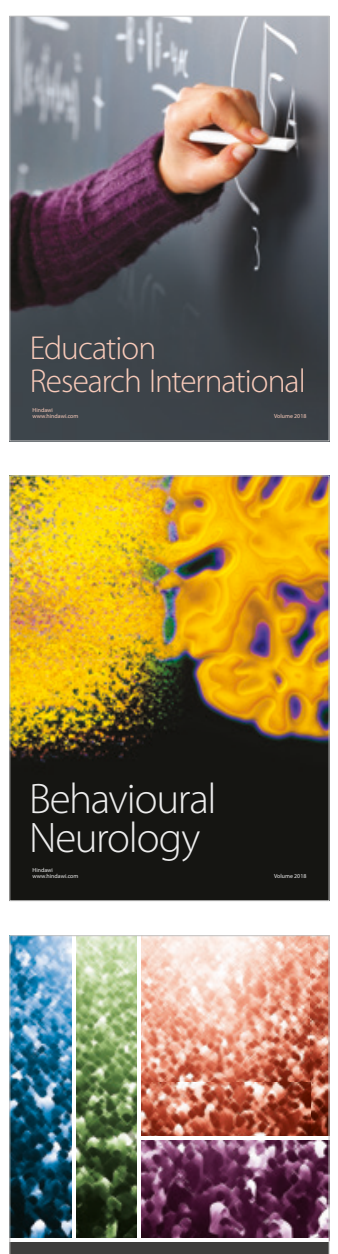

International Journal of

Population Research

$\underline{-m}$

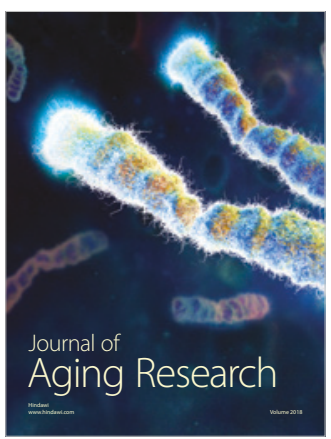

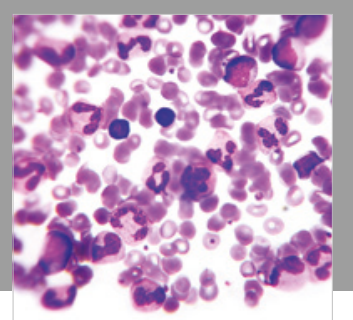

Pathology

Research International$$
=
$$

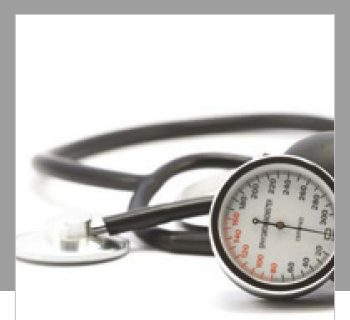

Nursing

Research and Practice

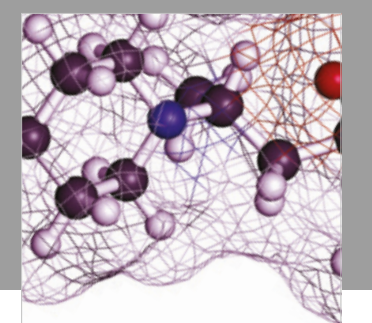

Pain

Research and Management

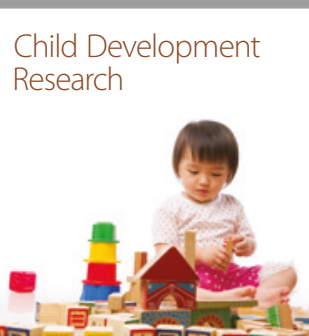

बाD

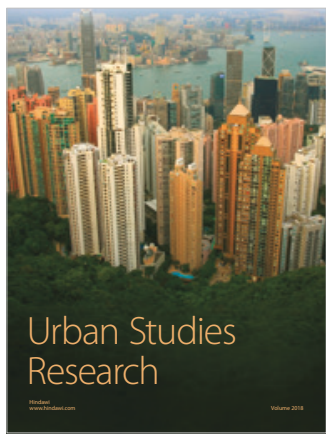

\section{Hindawi}

Submit your manuscripts at

www.hindawi.com
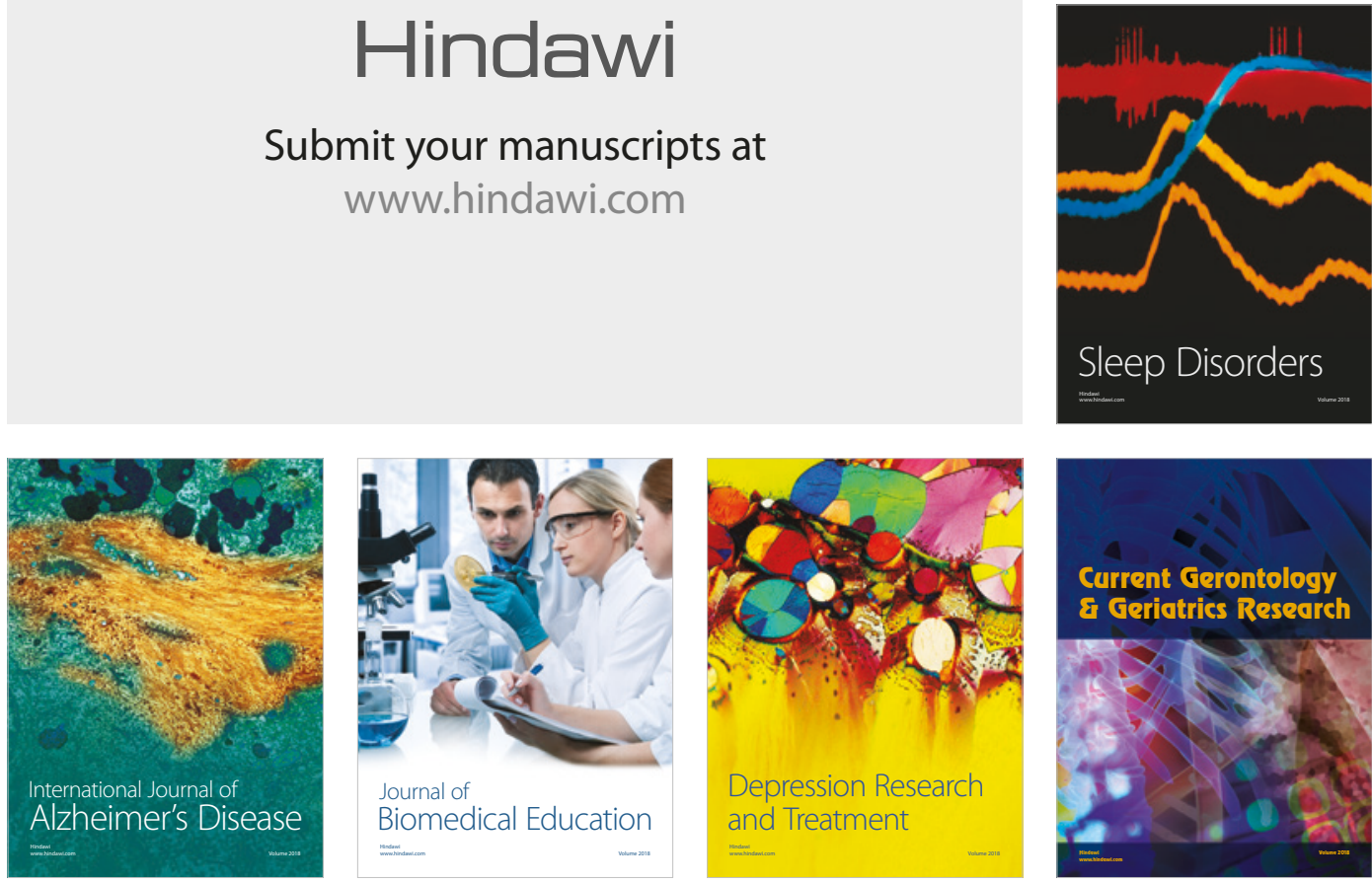

Journal of

Biomedical Education

$=$

smman

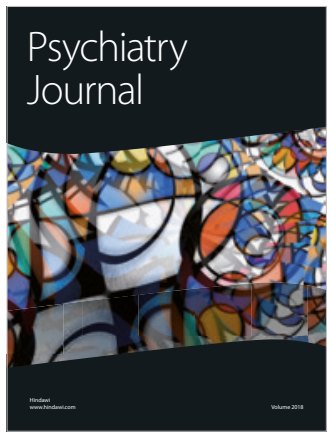

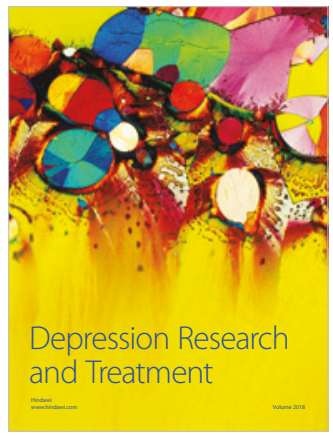
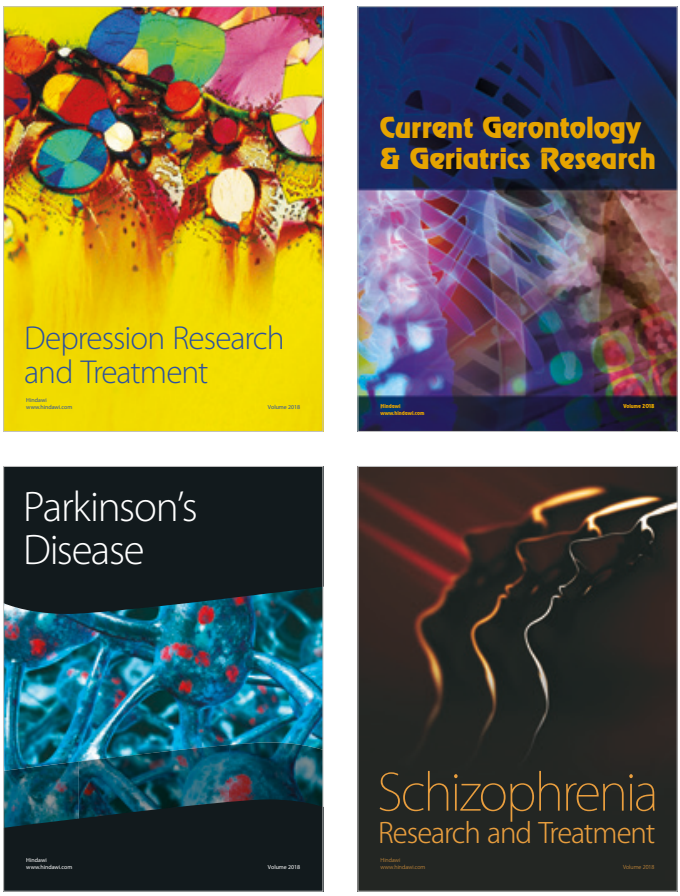